UDC 621. 315.612.8:535.215:537.226.4

$621,395.625$

\title{
光学的手法による強誘電体記録再生機構 の解析
}

$\begin{array}{llll}\text { 正員 新 妻 } & \text { 弘 明 } & \text { (東北大) } \\ \text { 非会員 大和田 } & \text { 淳 }- \text { (東北大) } \\ \text { 正員 佐 藤 } & \text { 利三郎 } & \text { (東北大) }\end{array}$

\section{1. まえがき}

強誘電体記録(1)-66)の解析は，とれまで波長加電極 幅に比べて十分長く，媒体内部の分極状態が媒体厚み 方向に均一で, 分極の方向は媒体表面に対して垂直で あるとした，媒体内部の分極状態まで立ち入らない回 路学的な手法でなされてきた 法により，強誘電体記録の長波長領域における記録再 生挙動はある程度説明することができた。

しかし，実際の記録再生系においては，媒体内部の 分極状態上記録再生特性は㳭くかかわり合っているこ とは明白であり，その記録再生機構を明らがするた めには記録媒体内部の分極状態まで考虑に入れた解析 が必要である。現に，現在の強誘電体記録では記録波 長が媒体厚の 2 倍以下になると，乙れまでの解析によ っては説明のつかない記録再生特性の低下驾見られ, とれが事実上記録周波数の上限を決定している。

本諭文では，強誘電体記録の記録媒体の分極状態を 電気光学效果を用いて测定し，その結果をもとに記録 時に抢ける記録媒体の分極過程について検討を加え， 媒体表面電荷，記録電極に上る䉓界の不均一性，媒体 の分極速度などを考慮に入れた記録過程のモデルを示 す。更に，そのモデルが実験事実をよく説明できるこ とを示す之共に，現在の強誘電体記録の記録密度の上 限を決めている要因を明らかにする。

An Analysis of Ferroelectric Recording Mechanism by Optical Measurements. By Hiroaki Niitsuma, Member, Jun-ichi Owjada, Non-member \& Risaburo Sato, Member (Faculty of Engineering, Tohoku University).

新妻弘明：正县，東北大学工学部通信工学科

大和田淖一：非会圆，菓北大学工学部通信工学科

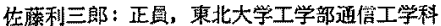

\section{2. 記録状態の光学測定}

〈2・1〉 赛験方法＼cjkstart記録媒体として透明強誘電体 セラミクス $\left(\mathrm{Pbo}_{0.94,} \mathrm{La0}, 06\right)\left(\mathrm{Zr}_{0,65}, \mathrm{Ti}_{0}, 35\right) \mathrm{O}_{3}$ ， 通称 PLZT 6/65/35 を用い，それに強誘電体記録䒾置 ${ }^{(3)}$ に

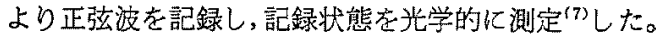

第 1 図江記録媒体の形状を示す。媒体の二面は光学 研摩されており，記録後この方向から残留分極分布が 観測できるようになっている。第1表に媒体の材料定 数を示す。第 2 図代微小媒体一の記録方法を示す。图 に見られる上うに，第 1 図に示した微小媒体は同一組 成のダミー媒体によりはさまれた状態で記録電極下を 通過し, 記録信号に対応した電荷が表面に注入される。 第 2 表代記録の諸条件を示す。

このようにして記録した媒体を，POS 形偏光顕微 鏡を用いた直交ニコル系により扁光測定し，媒体の残

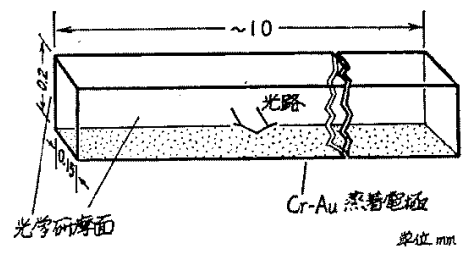

第 1 図 試料の形状

Fig. 1. Shape of recording medium.

第 1 表 記録媒体の材料定数

Table 1. Constants of recording medium.

\begin{tabular}{|c|c|}
\hline 成 & $\left(\mathrm{Pb}_{0.94,}, \mathrm{La}_{0.08}\right)\left(\mathrm{Zr}_{0,65}, \quad \mathrm{Ti}_{0.35}\right) \mathrm{O}_{3}$ \\
\hline 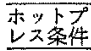 & 最㐭保持温应 $1,200^{\circ} \mathrm{C}$, 保持特間 20 硅間, 珐力 $210 \mathrm{~kg} / \mathrm{cm}$ \\
\hline 㮇電特性 & 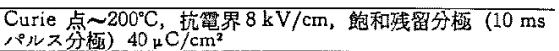 \\
\hline
\end{tabular}




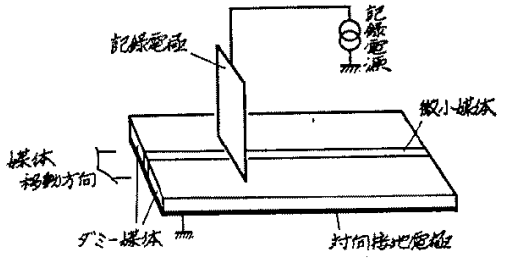

第 2 図 記録の方法

Fig. 2. Recording method.

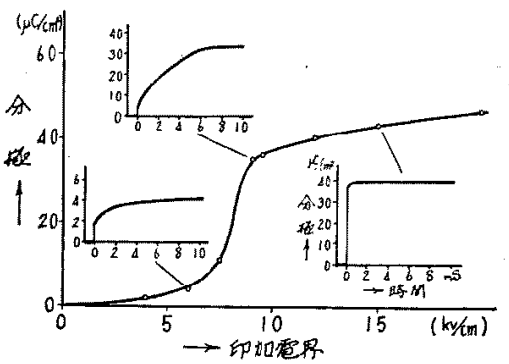

第 3 困 記録媒体の分極特性

Fig. 3. Polarizing characteristics of recording medium.

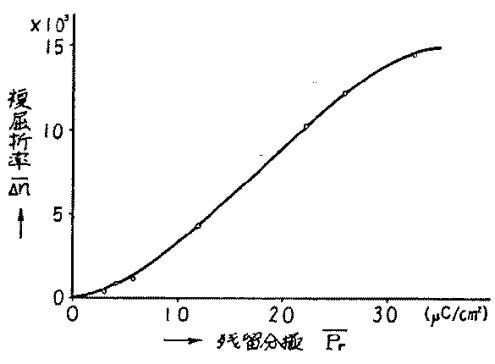

第 4 図 残留分極亡複屈折率の関係

Fig. 4. Relationship between remanent polarization and electrooptic birefringence.

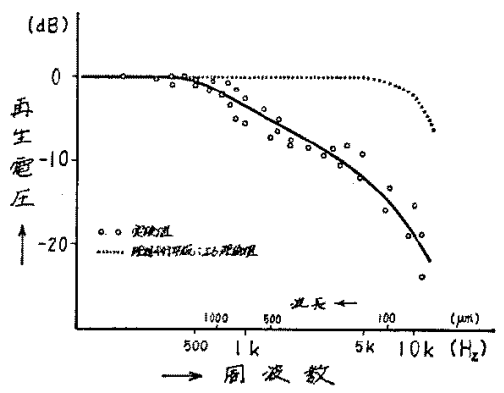

第 5 图 強誘電体記録の記録再生特性

Fig. 5. Recording-reproducing characteristic of the ferroelectric recording.
第 2 表 記録の諸条件

Table 2. Recording condition.

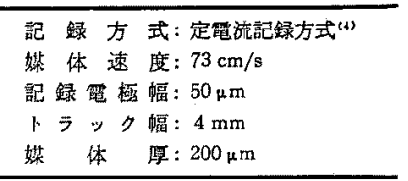

留分極によって生じた複屈折の大きさと方向の分布を 求めた。とのようにして測定した複屈折の大きさと方 向はそれぞれ残留分極の大きさと方向に対応してい $3^{(7)(9)}$ 。

第 3 図に実験に用いた試料を幅 $10 \mathrm{~ms}$ の定電圧パル スにより分極したときの分極特性を示す。そう入図は それぞれの電界におりる分極の時間変化を SawyerTower の回路により測定した結果である。第 4 困に は残留分極之複屈折率の関俰を測定した結果を示す。

$\langle 2.2\rangle$ 実験結果 第 5 図に正弦波を記録したと きの強誘電体記録の記録再生特性を示す。点線は“媒 体内部の分極分布が媒体面江垂直で，媒体厚み方向に 均一である”という理想平行平板近似に基づいた理論 值(4)(5)である。これに見られるように，実験值は周波 数 $500 \mathrm{~Hz}$ (波長 $1,400 \mu \mathrm{m}$ ) 付近加低下しており， 理論值と一致しない。

第6図は正弦波を記録したときの記録状態を光学的 に測定した結果である。図中，しま模様は分極の等高
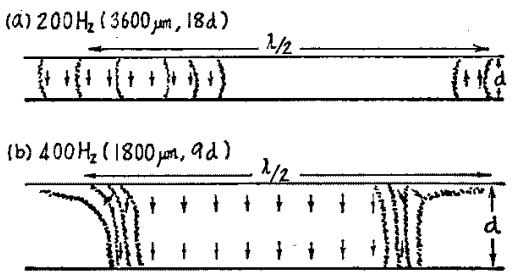

(c) $700 \mathrm{H}_{2}(1040, \mathrm{~m}, 5.2 \mathrm{~d})$

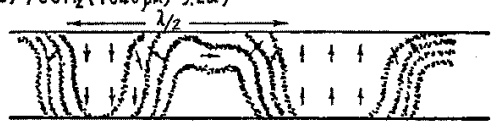

(d) $1.5 \mathrm{kH}_{\mathrm{L}}(48 \mathrm{T \mu n}, 2.4 \mathrm{~d})$

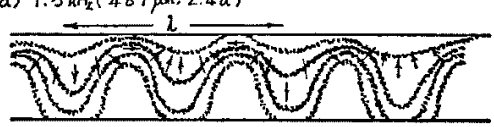

(e) $3 \mathrm{kH}_{2}(243 \mu \mathrm{m}, 1.2 \mathrm{~d})$

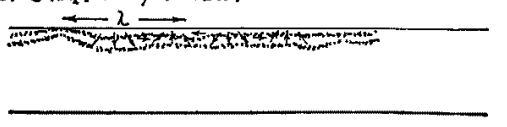

第 6 図媒体内 0 分極分布

Fig, 6. Remanent polarization distributions in recording medium. 


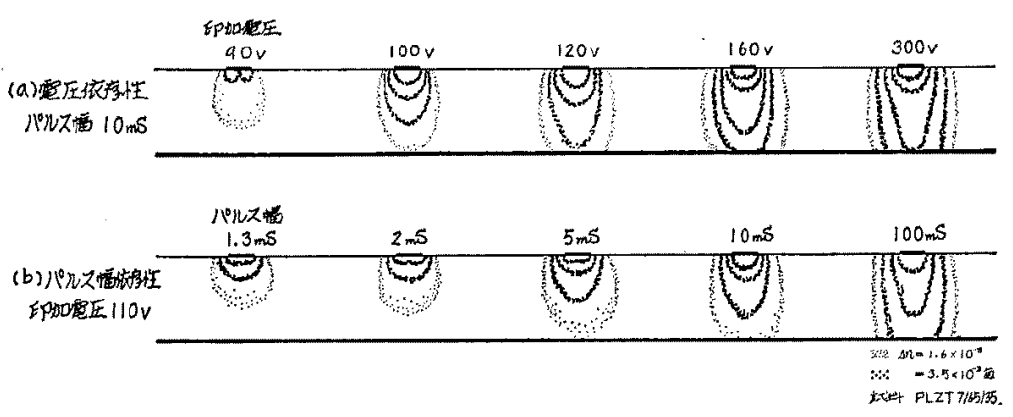

第 7 图 微小平行平板電極による記録媒体の分極

Fig. 7. Polarization of the recording medium by micro-parallel electrode.

線，矢印は分極の方向を表わしている。

とれによると，(a) 記録周波数 $200 \mathrm{~Hz}$ (波長 3,600 $\mu \mathrm{m}, 18 d, d$ : 媒体厚み) の場合には，分極は媒体厚 み方向にほ均一であり，記録信号に対㤂して媒体長 さ方向汇分極の大きさが変化している*。(b) $400 \mathrm{~Hz}$ (波長 $1,800 \mu \mathrm{m}, 9 d)$ ，(c) $700 \mathrm{~Hz}(1,040 \mu \mathrm{m}, 5.2$ d）之記録波長が短くなるる，媒体の表面付近のみが 水平方向に分極する領域吕現われる。（d）周波数が $1.5 \mathrm{kHz}$ (波長 $487 \mu \mathrm{m}, 2.4 d$ ) では，媒体厚み方向 の分極の不均一性汃著しくなり，(e) $3 \mathrm{kHz}(243 \mu \mathrm{m}$, $1.2 d)$ では表面のみがほほ様な強さで分極し，分 極方向が回転する上うな分極分布状態になる。

以上のように，長波長の理論と実窬結果が一致しな くなる $500 \mathrm{~Hz}(1,400 \mu \mathrm{m}, 7 d)$ 付近加ら，媒体内の 分極の不均一性が著しくなっている。

\section{3. 記録機構の検討}

強誘電体記録の記録機構を考えるにあたり，次の事 項を考慮する必要があろう。

（1）記録電極幅が媒体厚よりも小さいため，記録 電極と接地電極汃形成する電界は大きさ，方向と屯場 所的に一様でなく，電極端付近の分極の広がり，媒体 厚み方向の分極の浸透性などあ考虑しなりればならな いこと。

（2）移動電界により分極を行なっているため，媒 体の一点に着目すると, 時間的化大きさ, 方向が変化 する電界を受けること。

（3）記録時には記録電極加ら媒体表面に真電荷が 移動し(4)，記録後も媒体表面に残存するため，分極分 布はこの電荷分布による電界の影響を受けること。

（4）媒体の分極速度方雷界の大ささによって非直 線的に変化するため，媒体内部に分極速度の不均一性

*: このととは長波是領域においては理想平行平板近似による解析が罗 当であるととを示している。
が生ずるこよ。

(5) その他

本章では，てれらの要因を考虑しながら強誘電体記 録の記録過程の検討を行なう。

\section{〈3.1〉 微小電極による記録媒体の分極挙動}

強誘電体記録の記録過程に抢いて記録電極は対向接 地電極之微小平行平板電極を形成し，煤体を分極する。 そこで微小平行平板電極による記録禁体の分極挙動を 調べるために，第 1 図の試料の上面に微小電極をホ卜 エッチング法により装着し，分極条件に上る分極分布 の変化を光学的に観察した。第 7 図は試料厚 $200 \mu \mathrm{m}$ に対して，幅 $62 \mu \mathrm{m}$ の電極で定電圧パルス分極を行 なったときの分極分布の印加電生およびパルス幅依存 性を示す結果である。パルス幅依存性は媒体にステッ プ状の電圧を印加したときの分極の時間的な変化に対 応している。

図に見られるように，電極幅か詿料厚より手小さい ような微小平行平板電極による分極では，幅か十分大 きな電極による分極 (7) とは異なり，分極の厚み方向へ の浸透性加悪く，抗電界の 3 倍伅相当する電圧を印加 してあ電極下は一様に分極しない(8)。特に印加電壬や パルス幅が小さい場合にはこの傾向が著しい。

いま，媒体速度を $v$ ，電極幅を $2 L$ とす机ば媒体 の一点が電極下にある時間 $\tau$ は

$$
\tau=2 L / v
$$

であり, $v=73 \mathrm{~cm} / \mathrm{s}, 2 L=50 \mu \mathrm{m}$ では $\tau=0.068 \mathrm{~ms}$ である。促って，乙のような時間範囲では媒体は表面 付近のでく一部しか分極しないととになる。しかる に，第6図沙られるように，波長加媒体厚上りる十 分長い上うな場合には，媒体は媒体面に型直に加つ一 様に分極しており，とのと之は媒体は単仁記䩮電極加 作る電界によってのみ分極しているのではないてとを 示している。

〈3.2〉 表面電荷による媒体内の電界分布＼cjkstart前飾 
の実験により記録耗極の作る電界のみでは媒体が分極 していないことが明らがなった。電極による電界の ほ加注目されるのは，媒体表面の分布電荷化上る電 界である。強誘電体記録では磁気記録と異なり, 記録 過程において記録電極から媒体表面に真電荷が注入さ れ，それが電極下を通過後す媒体表面に残存している ことがこれまでの研究で明らかになっている(4)。そこ で本節では，誘電体表面にその電荷密度が場所の関数 であるような分布電荷を考え，それが誘電体内作る 電界分布を理論的に求めることにより，表面分布電荷 の影響を考える。

いま，第8図のように誘電体表面纪電荷密度 $\sigma$ が

$$
\sigma\left(x_{0}\right)=\sigma \sin \frac{2 \pi}{\lambda} x_{0}
$$

であるような分布電荷を考える。ここで誘電体仙次の 条件を満足するもの之仮定する。

（i）誘電特性は線形である。

(ii) 比誘電率 $\varepsilon_{s}$ が 1 より十分大きい。

また，系の奥行きは無限大とし二次元問題として考 える。

誘電体内部の電界分布は $\sigma\left(x_{0}\right)$ が作る電界上 $\sigma\left(x_{0}\right)$ の接地電極による影像電荷が作る電界を重畳したすの

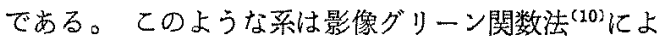
って解くことができ，誘電体内部の点 $P(x, y)$ におけ 万電界の $x$ 成分 $E_{x}$ および $y$ 成分 $E_{y}$ はそれぞれ

$$
\left.\begin{array}{l}
E_{x}=-\frac{\sigma}{\varepsilon_{0} \varepsilon_{s}} \cos \left(\frac{2 \pi}{\lambda} x\right) \cdot \frac{e^{-(2 \pi / \lambda) / y}-e^{(2 \pi / \lambda)(y-2 d)}}{1+e^{-(2 \pi / \lambda) \cdot 2 d}} \\
E_{y}=\frac{\sigma}{\varepsilon_{0} \varepsilon_{s}} \sin \left(\frac{2 \pi}{\lambda} x\right) \cdot \frac{e^{-(2 \pi / \lambda) y}+e^{(2 \pi / \lambda)(y+2 d)}}{1+e^{-(2 \pi / \lambda) \cdot 2 d}}
\end{array}\right\}
$$

と求められる*。

第 9 図は波長 $\lambda$ を夋えた場合の (3)式の計算結果 を図示したものである。夷線は等電界強度線，矢印は 電界の方向を表加しており，数值は $\lambda=\infty$ とした場合 の電界強度 $\sigma / \varepsilon_{0} \varepsilon ， に$ 対する相対值である。てれによ ると，波長 $\lambda$ が誘電体厚み $d$ に比べ十分長い上うな 場合には，電界は接地電極面に瑟直で，大きさが厚み 方向にほほ一様になるが，波長が短くなるにつれて厚

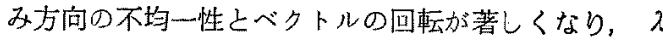
$=3 d$ では誘電体表面に電界か策中し，その大きさが $x$ 方向にほぼ一様でベクトルのみが回転するような電 界分有になる。乙れらの傾向は，第6図の媒体内の分 極状態の測定結果に酷似しており，強誘電体記録の記 録過程では，媒体表面の分布電荷苏分極状態を決定す るのに大きな役割を果たしているととを示している。

*: 付録厸照

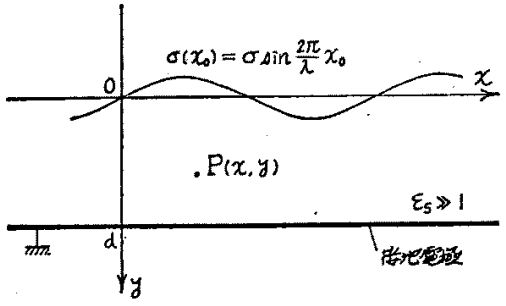

第 8 図 表面分布電荷如作る電界分布の計算 Fig. 8. Calculation of electric field distribution produced by surface charge distribution.

(a) $\lambda=20 d$

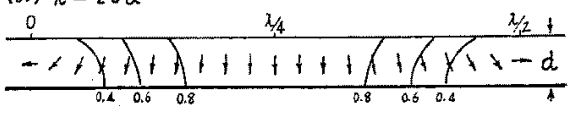

(b) $\lambda=10 d$

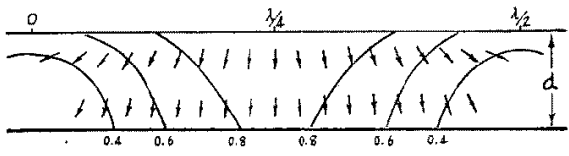

(c) $\lambda=5 d$

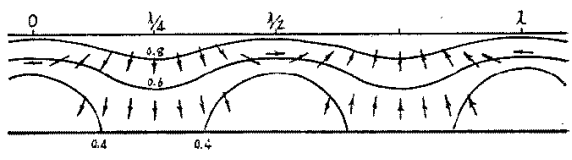

(d) $\lambda=4 d$

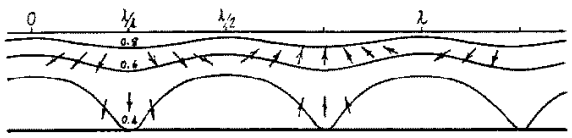

(e) $l=3 d$

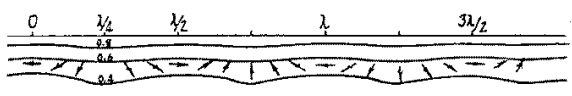

第 9 図 表面分布電荷が作る電界分布

Fig. 9. Electric field distribution in dielectrics produced by surface charge distribution.

(3)式において接地電極におりる電界強度が誘電体 表面の電界强度の $1 / 2$ になる波長 $\lambda_{\varepsilon}$ を計算すると

$$
\lambda_{c}=4 d \text {. }
$$

となる。奏際の記録系で媒体内の分極が不均一にな b，分極の方向の回転が著しくなる波長は $\lambda=3 \sim 5 d$ であり（4)式の結果とほぼ一致している。

〈3.3〉記録過程のモデル 以上の結果をもとに 考光た記録過程のモデルを第 10 困に示す。同図にお いて記録過程は次のよう記説明される。（a）媒体の一 点が電極下を通過すると，定電流記録方式 ${ }^{(4)}$ により記 録電極加ら媒体表面に記録信号に応じた電荷が注入さ 
(a)

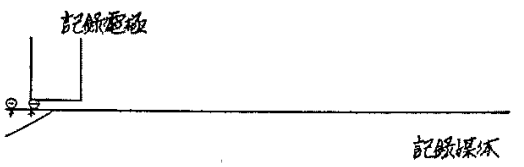

(b)

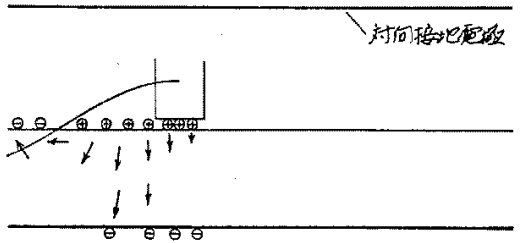

(c)

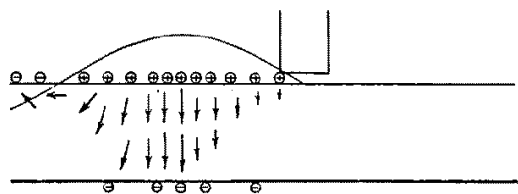

(d)

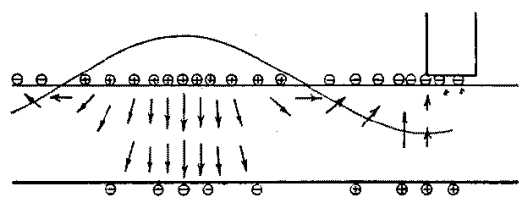

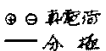

第 10 図 記録過程のモデル

Fig. 10. Model of recording process.

れる。しかし，電極下を通過している時間範囲では表 面のみが分極し，厚み方向へは分極はほとんど浸透し ない。（b)〜 (d) 記録電極下を通過後，残存している 媒体表面上の分布電荷之接地電極上の誘導電荷により 徐々に分極が成長し，分極分布が決定される。

以上の記録過程において重要な要因は媒体の分㥛速 度である。一般汇強誘電体せラミクスの分極速度は印 加電界に強く依存し，抗電界 $E$ 。上りあ大きな電界を 印加した場合は比較的速いが，抗電界以下ではかなり 遅くなる。本実験に用いたPLZT 6/65/35 の場 合，第 3 図のそう入図に見られるように $2 E_{t}$ の電界 では $100 \mu \mathrm{s}$ 以下で分極が完了するが， $E_{c}$ 付近では 5 10ms か力か，1/2 $E_{\text {c }}$ では $100 \mathrm{~ms}$ でも分極は一定 值に達しない。このため，特に媒体の記録電極加ら遠 か部分では電界が弱いために分極の成長が遅く，分極 が短時間では浸透し得なくなる。一方，笔極下を通過 している時間籁囲では分極が完了しないに㤈から ず，定電流記録方式に上り，媒体表面には信号に対応 した電荷が注入されれている。このため分極電荷は表面 電荷を完全に中和することができず，電極下を通過後 あ媒体内には電界が存在することになる。この電界が 電極通過後分極を䋡々に成長させるととになるものと
考元られる。

以上の上うに，現在の強誘電体記録では，媒体の分 極速度の遐さに起因して，媒体内の分極状態は主に媒 体表面の分有電荷により決定され，それが記録密度の 上限を決めているもの上考えることができる。

このほ加化，媒体の一点が受ける電界の方向が時間 と共に変化するために生ずる効果, 磁気記録の場合(11) のように媒体の分極が回枟分極モードなど特殊な分極. モードを形成するととによる効果，媒体の電気ひずみ 効果による応力場の影響(8)などが考えられるが，現在 の強誘電体記録では表面電荷に上る効果が大きく，乙 れらの効果は顕著には現われていないあのと考えられ る。

\section{4. むすび}

強誘電体記録の記録媒体の分極状態を電気光学効果 を用いて測定し，更に微小平行平板電極に㧍ける強誘 電体セラミクスの分極挙動，誘電体表面に正弦波状の 分布電荷が存在している場合の誘電体内の電界分布な どを検討するととにより，強誘電体記録の記録機構の 解析を行なった。その結果, 現在の強誘䉓体記録にお いては，記録電極が作る電界では媒体が裴面付近しか 分極せず，媒体内の分極分布は主に記録電極加ら注入 され媒体表面に残存している分布電荷による電界によ って決定されることを示し，その原因が媒体の分極速 度の掘さにあることを明らか比した。また，ての効果 加現在の強誘電体記録の上限を決めていることを示し た。

本解析の結果，強誘電体記録の記録機棏の一部が明 らかになりてれまでの解析では説明できなかった特 性の幾つかが解明された。これらの結果は，今後強誘 電体を用いた記録・記憶システムの解析を行なう場合 や高密度化を図るにあたり有効であると思われる。

最後に，本実験汇用いた PLZT 試料を提供して下 さった八戸工業大学 増田助教授，微小試料の作製を 招愿いした本学教貝部地学科 日野さんに感謝の意を 表します。

(昭和 54 年 3 月 19 日受付)

\section{文献}

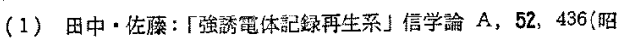
44-11)

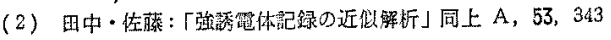
(昭 45-7)

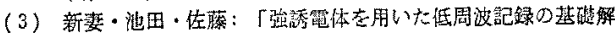
折」䉓学諭 A, 94, 69 (昭 49-2)

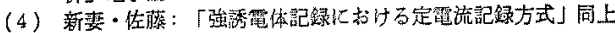
A , 95, 57 (昭 50-2)

昭 $54-12$ 


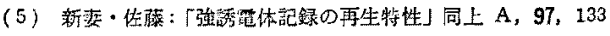
(吸 $52-3$ )

(6) H. Nitsuma, et al.: "Some Aspects of Ferroelectric Recording", Proc. of the 1st Meeting on Ferroelectric Materials and Their Application R-1, 97 (1977)

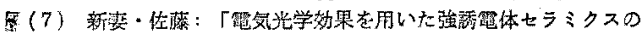
分栖分布の测定」電学劄 A, 98，151 (明 53-3)

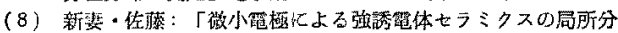
極特性」同上A，99，566(昭 54-12)

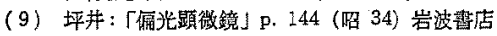

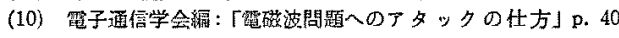
(昭 52-12)

(11) S. Iwasaki \& K. Takemura: "An Analysis for the Circular Mode of Magnetization in Short Wavelength Recording", IEEE Trans. Magnetics, MAG-11, 1173, (1975)

\section{付 録}

（3）式の求め方 誘電体上に電荷が存在する系の 電界分布は，誘電体境界条件を満足するように影像を 構成し，それらの影像電荷群化よる電界を重畳するこ とによって求められる。本論文のモデルの場合には， 誘電体の比誘電率 $\varepsilon_{s}$ が 1 より十分大きいため，表面 分布電荷加出万電束はほとんど誘電体内を通る。分 布電荷が(2)式のように与えられれば，接地電極によ る影像䉓荷は接地電極と詨称に $y=2 d$ 平面上で

$$
\sigma\left(x_{0}, 2 d\right)=-\sigma \sin \frac{2 \pi}{\lambda} x_{0}
$$

である。そして，(2)式扣上び(付 1)式の電荷分布が

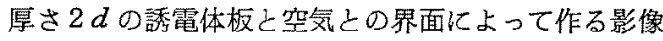
電荷は $y= \pm 2 d, \pm 4 d, \cdots, \pm 2 n d, \cdots(n=1,2$ ， $3, \cdots)$ の平面上に存在し，その値は

$$
\left.\left.\begin{array}{rl}
\sigma\left(x_{0}, 2 n d\right)= & (-1)^{n} \sigma \sin \frac{2 \pi}{\lambda} x_{0} \\
& (n= \pm 1, \pm 2, \cdots)
\end{array}\right\} \ldots \text { (付 } 2\right)
$$

となる。(付 2$)$ 式の微小楅 $d x_{0}$ の带状の電荷は，

$$
d \sigma\left(x_{0}, 2 n d\right)=(-1)^{n} \sigma \sin \left(\frac{2 \pi}{\lambda} x_{0}\right) \cdot d x_{0}
$$

であり，乙れが媒体内部の点 $P(x, y)$ 亿作る電界 $d E$ は次式で与えられる。

$$
d E=\frac{(-1)^{n} \sigma \sin \left(\frac{2 \pi}{\lambda} x_{0}\right) \cdot d x_{0}}{2 \pi \varepsilon_{0} \varepsilon_{s} \sqrt{\left(x-x_{0}\right)^{2}+(y-2 n d)^{2}}}
$$

従って, $d E の x$ 方向成分 $d E_{x}, y$ 方向成分 $d E_{\nu}$ は

$$
\left.\begin{array}{l}
d E_{x}=\frac{(-1)^{n} \sigma\left(x-x_{0}\right) \sin \left(\frac{2 \pi}{\lambda} x_{0}\right) d x_{0}}{2 \pi \varepsilon_{0} \varepsilon_{s}\left\{\left(x-x_{0}\right)^{2}+(y-2 n d)^{2}\right\}} \\
d E_{y}=\frac{(-1)^{n}(y-2 n d) \sin \left(\frac{2 \pi}{\lambda} x_{0}\right) d x_{0}}{2 \pi \varepsilon_{0} \varepsilon_{s}\left\{\left(x-x_{0}\right)^{2}+(y-2 n d)^{2}\right\}}
\end{array}\right\}
$$

となる。（付5)式を $x_{0}$ について $(-\infty, \infty)$ で皘分 するととにより， $y=2 n d$ の影像電荷が点 $P$ に作る 電界 $E_{x n}, E_{y n}$ が次のように計算できる。

$$
\left.\left.\begin{array}{rl}
E_{x n}= & -(-1)^{n} \frac{\sigma \cos \left(\frac{2 \pi}{\lambda} x\right)}{2 \varepsilon_{0} \varepsilon_{s}} \\
& \times \exp \left\{-\frac{2 \pi}{\lambda}|y-2 n d|\right\} \\
E_{y n}= & (-1)^{n} \frac{\sigma \sin \left(\frac{2 \pi}{\lambda} x\right)}{2 \varepsilon_{0} \varepsilon_{s}} \\
& \times \exp \left\{-\frac{2 \pi}{\lambda}|y-2 n d|\right\}
\end{array}\right\} \ldots \text { (付 } 6\right)
$$
式が求まる。 